\title{
Methamphetamine Neurotoxicity Involves Vacuolation of Endocytic Organelles and Dopamine-Dependent Intracellular Oxidative Stress
}

\author{
Joseph F. Cubells, ${ }^{\text {a }}$ Stephen Rayport, Geetha Rajendran, ${ }^{\mathrm{b}}$ and David Sulzer \\ Departments of Psychiatry, Anatomy, and Cell Biology, and Center for Neurobiology and Behavior, Columbia University, \\ New York. New York 10032 and Department of Neuropathology, New York State Psychiatric Institute, New York, New \\ York 10032
}

\begin{abstract}
Methamphetamine (MA) produces selective degeneration of dopamine (DA) neuron terminals without cell body loss. While excitatory amino acids (EAAs) contribute to MA toxicity, terminal loss is not characteristic of excitotoxic lesions nor is excitotoxicity selective for DA fibers; rather, EAAs may modulate MA-induced DA turnover, suggesting that DA-dependent events play a key role in MA neurotoxicity. To examine this possibility, we used postnatal ventral midbrain DA neuron cultures maintained under continuous EAA blockade. As in vivo, MA caused neurite degeneration but minimal cell death. We found that MA is a vacuologenic weak base that induces swelling of endocytic compartments; MA also induces blebbing of the plasma membrane. However, these morphological changes occurred in MA-treated cultures lacking DA neurons. Therefore, while collapse of endosomal and lysosomal $\mathrm{pH}$ gradients and vacuolation may contribute to MA neurotoxicity, this does not explain selective DA terminal degeneration. Alternatively, MA could exert its neurotoxic effects by collapsing synaptic vesicle proton gradients and redistributing DA from synaptic vesicles to the cytoplasm. This could cause the formation of DA-derived free radicals and reactive metabolites. To test whether MA induces oxidative stress within living DA neurons, we used 2,7-dichlorofluorescin diacetate (DCF), an indicator of intracellular hydroperoxide production. MA dramatically increased the number of DCF-labeled cells in ventral midbrain cultures, which contain about $30 \%$ DA neurons, but not in nucleus accumbens cultures, which do not contain DA neurons. In the DA neuron cultures, intracellular DDF labeling was localized to axonal varicosities, blebs, and endocytic organelles. These results suggest that MA redistributes DA from the reducing environment within synaptic vesicles to extravesicular oxidizing environments, thus generating oxygen radicals and reactive metabolites within DA neurons that may trigger selective DA terminal loss.
\end{abstract}

\footnotetext{
Reccived Apr. 20, 1993; revised Sept, 28, 1993; accepted Oct. 4, 1993

We thank David Pierson for performing the methamphetamine radioimmunoassays; Robert Burke, Jean Cadet, Andrew Ewing, and Serge Przedborski for critical discussion; and Anne Li for technical assistance. This work was supported by NIH Grants DA07418 (D.S.). MH00705 and MH44736 (S.R.), and a BRSG award (J.F.C.).

Correspondence should be addressed to Dr. David Sulzer, Department of Psychiatry, Columbia University, New York State Psychiatric Institute, Unit 62, 722 West 168 th Street, New York, NY 10032

"Present address: Bourne Laboratory and Laboratory of Molecular Neurobiology, Department of Psychiatry, Cornell University Medical College, 21 Bloomingdale Road, White Plains, NY 10605.

Present address: New York Medical College, Valhalla. NY 10595.

Copyright c) 1994 Society for Neuroscience 0270-6474/94/142260-12\$05.000
}

IKey words: ammonium chloride, amphetamine, cell culture, 2,7-dichlorofluorescin diacetate, dopamine, hydrogen peroxide, nucleus accumbens, oxygen radicals, oxidative stress, superoxide dismutase, ventral tegmental area]

The psychostimulant methamphetamine (MA) is commonly abused for its rewarding effects, which are thought to result from dopamine (DA) release in the nucleus accumbens (nAcc; Cho, 1990: Wise and Hoffman, 1992). MA administration also induces a selective degeneration of striatal DA terminals (Seiden and Ricaurte, 1987). This effect appears to be DA dependent since it is attenuated by inhibition of DA synthesis (Gibb and Kogan, 1979; Fuller and Hemrick-L uecke, 1982; Schmidt et al., 1985). However, NMDA receptor antagonists also reduce MA neurotoxicity (Sonsalla et al., 1989, 1991). Recent studies empluying in wo microdialysis have linked the protective effect of MK-801 to the ability of this drug to diminish MA-induced striatal DA overflow (Marshall et al., 1993). Similarly, decreases in striatal DA overflow appear to underlie the protective effect of $D_{1}$ and $D_{2}$ antagonists (O'Dell et al., 1993). Thus, several strategies for reducing MA neurotoxicity appear to sharc as a common mechanism the attenuation of MA-induced DA release, argung for the importance of DA itself as a key mediator of MA neurotoxicity.

DA readily oxidizes at physiological $\mathrm{pH}$ to form potentially toxic metabolites including hydroxyl radical, superoxide radical, hydrogen peroxide, and quinones (Graham et al.. 1978; Cohen, 1984; Graham, 1984; Slivka and Cohen, 1985). Seiden and Vosmer (1984) originally suggested a direct role for DA-dependent oxidation in MA neurotoxicity by demonstrating the presence of a compound chromatographically indistinguishable from 6-hydroxydopamine (6-OHDA) in the brain after MA administration. Although this finding remains controversial (Rollema et al., 1986; Fuller, 1991), the obscrvation that antioxidants such as ascorbate and vitamin E partially antagonize MA neurotoxicity (De Vito and Wagner, 1989) provides further evidence that MA neurotoxicity could involve oxidative stress.

Amphetamines are weak bases that collapse intracellular $\mathrm{pH}$ gradients in acidic organelles that include lysosomes, endosomes, and synaptic vesicles (Sulzer and Rayport, 1990). Acidotropic uptake of MA could cause osmotic swelling (Sulzer and Holtzman, 1989) and explain the vacuole formation seen in cultured neurons exposed to MA (Cubells et al., 1991; Bennett et al., 1993). Furthermore, since amphetamines displace DA from synaptic vesicles to the cytoplasm (Sulzer and Rayport, 1990; Sulzer et al., 1992a,b) MA might promote intraneuronal DA-dependent oxidative stress. Normally, synaptic vesicles 
maintain catecholamines in a reduced state due to their acidic pH and probable high levels of ascorbate (Beers et al., 1986; Njus et al., 1986; Johnson, 1988). If displaced to the cytoplasm, DA would likely undergo both auto-oxidation and enzymatic oxidative metabolism by monoamine oxidase (MAO), leading to the formation of hydrogen peroxide, free radicals, and quinones (Graham et al., 1978; Slivka and Cohen, 1985). In this article, we show that MA exerts both of these potentially neurotoxic effects: (1) a swelling of endocytic organelles that occurs in all neurons as well as glia, and (2) a redistribution of DA from reducing to oxidizing environments that leads to DAdependent oxidative stress within neurons. We thus propose that DA-dependent oxidative stress may be the initial event in MA neurotoxicity.

A preliminary presentation of this work has been made in abstract form (Cubells et al., 1991).

\section{Materials and Methods}

Cell culture. Culture techniques followed those previously described (Rayport et al., 1992) with the addition of glutamate antagonists. Briefly, postnatal day $1-3$ rat pups were anesthetized with $5 \mathrm{mg}$ of ketamine intraperitoneally followed by hypothermia. A ventral midbrain segment including both the ventral tegmental area (VTA) and substantia nigra (SN) was dissected from a $2-\mathrm{mm}$-thick coronal slice at the level of the midbrain flexurc; the $\mathrm{nAcc}$ was dissected from a horizontal slice at the level of the anterior commissure. The regions of interest were cut into $1 \mathrm{~mm}^{3}$ cubes and enzymatically dissociated with papain (Worthington; $10 \mathrm{U} / \mathrm{ml}$ ) in an oxygenated bicarbonate-buffered saline (cf. Baughman et al.. 1991) for $2 \mathrm{hr}$ at $32^{\circ} \mathrm{C}$. The tissue cubes were triturated and the resulting cell suspension plated onto monolayers of cortical astrocytes. Individual cultures contained about 20,000 neurons and ventral midbrain cultures contained about 5 pmol of DA (Sulzer et al., 1993). Cultures were maintained at $35^{\circ} \mathrm{C}$ in $5 \% \mathrm{CO}_{2}$ in serum-free media supplemented with $1 \%$ calf serum (Hyclone), containing $0.5 \mathrm{~mm}$ kynurenate (a level that antagonizes both NMDA and AMPA receptors; Watkins and Collingridge, 1989), 0.25\% albumin, $0.5 \mathrm{~mm}$ glutamine, $100 \mu \mathrm{g} / \mathrm{ml}$ transferrin, $15 \mu \mathrm{M}$ putrescine, $30 \mathrm{nM} \mathrm{Na} \mathrm{SeO}_{3}, 30 \mathrm{nM} \mathrm{T}_{3}, 25 \mu \mathrm{g} / \mathrm{ml}$ insulin, $200 \mathrm{~nm}$ progesterone, $125 \mathrm{~nm}$ cortisol, $5 \mu \mathrm{g} / \mathrm{ml}$ superoxide dismutase, and $10 \mu \mathrm{g} / \mathrm{ml}$ catalase (all from Sigma). Proliferation of nonneuronal cells was suppressed by addition of $25 \mu \mathrm{M} 5$-fluorodeoxyuridine with $70 \mu \mathrm{M}$ uridine (Sigma) to the medium $1 \mathrm{~d}$ after plating. MA was introduced directly into the kynurenate-containing culture medium by dilution of a $1000 \times$ stock for 10 and $100 \mu \mathrm{M}$ MA exposures or of a $100 \times$ stock for 500 and $1000 \mu \mathrm{M}$ MA exposures. Radioimmunoassay (High Specificity Methamphetamine Abuscreen system, Roche Diagnostics) showed that MA concentrations in the medium were constant over $6 \mathrm{~d}$ (the maximum exposure duration).

Viability assays. Calcein-acetoxymethyl ester (calcein AM; $3.00 \mu \mathbf{M}$ ) and ethidium homodimer- $1(3.75 \mu \mathrm{M})$ were used to identify living and dead cells, respectively (Live/Dead Assay, Molecular Probes). Calcein AM is membrane-permeable dye that is cleaved by intracellular esterases to produce an impermeant green-wavelength fluorophore in living cells, while ethidium homodimer is a red-wavelength fluorophore that selectively permeates the broken membranes of dying cells and stains their nuclei. To assess neuronal viability, cultures were stained for 75 $\min$ at $32^{\circ} \mathrm{C}$ with the two dyes, rinsed with phosphate-buffered saline, and examined under fluorescein epifluorescence. This assay clearly distinguished living from dead neurons as all neurons were labeled and none were double labeled. The frequency of dead neurons in each treatment was compared to that expected on the basis of the control using $\chi^{2}$ tests. There were no differences between treatments in total numbers of neurons per field (control dishes had 32.9 neurons per $25 \times$ field, while dishes exposed to the maximum $1000 \mu \mathrm{M}$ dose of MA for $6 \mathrm{~d}$ had 32.5 neurons per $25 \times$ field; $t=0.07$, df $=25, p>0.9$ ), showing that the viability assays were not skewed by disintegration of dead cells over the course of the experiment.

Quantitative analvsis of MA-induced neurite loss. DA neurons and their processes were visualized hy tyrosine hydroxylase $(\mathrm{TH})$ immunocytochemistry using standard methods (Rayport et al., 1992). The first $10 \mathrm{TH}$ ' ncurons encountered in a random scan of each dish were evaluated for ncurite arborization by an observer blind to the treatment

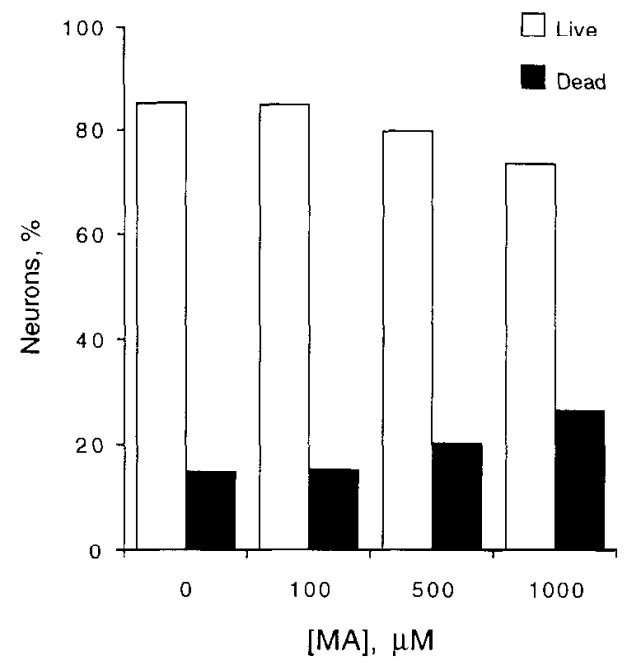

Figure 1. MA produces limited cell dcath in ventral midbrain culture. Cultures were exposed to MA from day 10 through day 15 in vitro; MA levels were shown to be stable by radioimmunoassay (data not shown). Live and dead cells were counted after labeling with calcein AM and ethidium homodimer. The highest exposure to $\mathrm{MA}(1 \mathrm{mM})$ increased the percentage of dead neurons from $15 \%$ to $26 \%\left(\chi^{2}=46.9, \mathrm{df}=1, p\right.$ $<0.001$, compared to that expected on the basis of the control). Exposure to $100 \mu \mathrm{M}$ or $500 \mu \mathrm{M}$ MA did not produce significant increases in frequencies of dead neurons $\left(\chi^{2}=0.062\right.$ and $0.355, \mathrm{~d} f=1$, respectively; $n=426-487$ neurons per condition).

condition. Processes of $\mathrm{TH}^{+}$neurons were quantified by placing each cell body in the center of a $40 \times$ scope field (radius of $250 \mu \mathrm{m}$ ) and counting the number of primary neurites that reached, or whose branches reached, the perimeter of the field. Experiments were performed in matched sets of sister cultures and were repeated in five to seven culture dishes per treatment group. Data reported were from two groups of cultures prepared on different days. Frequency distributions for each treatment group were generated by assigning each neuron to a bin corresponding to $0,1,2,3$, or $\geq 4$ neurites extending to the field perimeter (fewer than $3 \%$ of neurons had $>4$ neurites). These values are discrete nominals and were analyzed by nonparametric statistics. Contingency table analysis of the pooled data (Dowdy and Wearden, 1983) rejected the null hypothesis that the arborization index distributions were homogeneous across treatments $\left(\chi^{2}=51.68, \mathrm{df}=16 ; p<0.001\right)$. Distributions were then compared between individual treatments using $\chi^{2}$ goodness-of-fit tests (Zar, 1984).

Endocytic labeling. Cultures were exposed to green fluorescent latex microspheres (1:1000; Luma-Fluor) for 18-24 hr. Cultures were then rinsed with physiological saline and control images of scveral fields recorded. MA or other weak bases were added for $1-3 \mathrm{hr}$ and images of the same fields rerecorded.

$D C F$ spectrofluorometry. Aliquots of 1 mM 2,7-dichlorofluorescin diacetate (DCF; Molecular Probes) were prepared in ethanol and stored at $-85^{\circ} \mathrm{C}$. To determine if DA auto-oxidation increased DCF fluorescence, DCF was first deesterified by incubating $0.5 \mathrm{ml}$ of $1 \mathrm{~mm} \mathrm{DCF}$ in $2 \mathrm{ml}$ of $0.01 \mathrm{~N} \mathrm{NaOH}$ at $20^{\circ} \mathrm{C}$ for $30 \mathrm{~min}$, after which the $\mathrm{pH}$ was neutralized with $10 \mathrm{ml}$ of $50 \mathrm{~mm}$ Tris, pH 7.2 (Cathcart et al., 1983). $\mathrm{DA}$ at a final concentration of 0,1 , or $10 \mathrm{~mm}$ was added to the deesterified DCF, $150 \mu \mathrm{M}$ final concentration, in $1.5 \mathrm{ml}$ of $50 \mathrm{~mm}$ Tris, $\mathrm{pH}$ 7.2. The increase in fluorescence over time was measured at room temperature with a spectrofluorometer (Varian SF-330) set at an excitation wavelength of $505 \mathrm{~nm}$ and an emission wavelength of $525 \mathrm{~nm}$.

$D C F$ in neuronal culture. Aliquots of $10 \mathrm{~mm}$ DCF were prepared in dimethyl sulfoxide and stored at $-85^{\circ} \mathrm{C}$. Immediately before use, an aliquot was diluted to $1 \mu \mathrm{M}$ in $32^{\circ} \mathrm{C}$ minimal essential medium. Cultures were incubated for $15 \mathrm{~min}$ and then rinsed twice with oxygenated physiological saline (135 mM NaCl, $3 \mathrm{~mm} \mathrm{KCl}, 2 \mathrm{~mm} \mathrm{CaCl}, 2 \mathrm{~mm} \mathrm{MgCl}$, $10 \mathrm{~mm}$ glucose, and $10 \mathrm{~mm}$ HFPES, $\mathrm{pH} 7.3$ ) at $32^{\circ} \mathrm{C}$. To avoid photodynamic damage, the excitation beam was attenuated with a $10 \%$ neutral density filter and low-light images recorded using a chilled CCD camera (Photometrics); digital images werc stored to disk and processed 

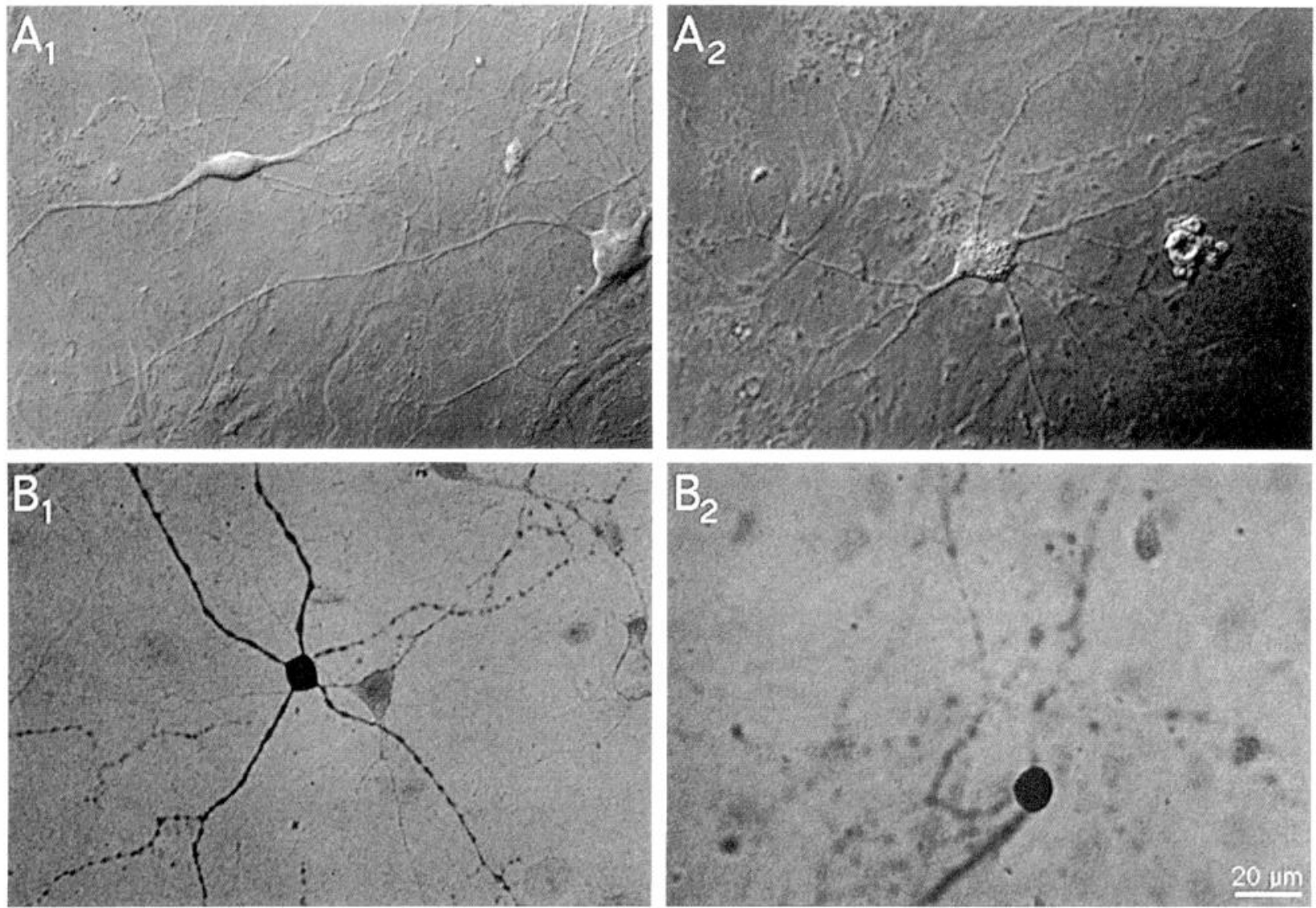

Figure 2. MA produces neurite degeneration, vacuolation, and blebs. $A_{t}$, Nomarski image of representative neurons from control ventral midbrain cultures. Note the relatively smooth appearance of the cell body and long, thin processes. $A_{2}$, Nomarski image of representative neurons from ventral midbrain cultures treated with $500 \mu \mathrm{M}$ MA for $1 \mathrm{~d}$. Note the vacuolated appearance of the cell body and the swollen processes of the neuron on the left. The neuron on the right has apparently lost its processes and displays several blebs; such cells were still alive by fluorescence viability assay. Such cells are identified as neurons because neurites can be observed at intermediate stages of degeneration (compare Fig. 8) and because oligodendrocytes are both rare and identifiable by morphological criteria. $B_{1}$, A representative DA neuron from a control culture stained for TH. Note the long processes including a putative axon studded with varicosities. Such varicosities contain DA synaptic vesicles and mitochondria (Sulzer and Rayport, 1990; Rayport et al., 1992). $B_{2}$, DA neuron from a culture stained for TH after exposure to $100 \mu \mathrm{M}$ MA for 6 d. Note the remnants of processes, which were not visible under Nomarski optics prior to TH staining, suggestive of cytoskeletal collapse.

using NIH IMAGE (Wayne Rasband; available on Internet via anonymous FTP from zippy.nih.nimh.gov in the directory /pub/nih-image) Labeled and unlabeled neurons were counted by a second observer blind to both the treatment and the cellular origin of each culture. A minimum of 300 neurons per condition were counted. To assess whether imaged cells were dopaminergic, the fields examined were circled with a diamond objective marker, cultures were processed for TH immunocytochemistry, and the images were correlated.

\section{Results}

Morphological effects of MA exposure

In vivo, MA causes degeneration of DA processes but not DA cell bodies (Ricaurte et al., 1982, 1984). Similarly, in postnatal ventral midbrain cultures maintained in $0.5 \mathrm{~mm}$ kynurenate, MA caused no reduction in numbers of viable neurons except at suprapharmacologic concentrations above $500 \mu \mathrm{M}$ (Fig. 1); however, profound morphological changes were evident both in neurons and glia. Under Nomarski optics, neurons in control cultures appeared relatively smooth (Fig. $2 A$ ), whereas numerous spherical cytoplasmic structures imparted a rough, grainy appearance to MA-treated neurons (Fig. 2B). These vacuoles were visible in all MA-treated neurons and glia, even after exposures of cultures to as little as $10 \mu \mathrm{M}$ MA for $1 \mathrm{~d}$ or to 100 $\mu \mathrm{M}$ MA for $2 \mathrm{hr}$. Under phase-contrast optics, the MA-induced vacuoles were identical in appearance to those observed by Bennett et al. (1993); they also resembled weak base-induced structures in retinal neurons (Sulzer and Holtzman, 1989). Larger ovoid structures, often protruding above the surfaces of cell bodies and processes, frequently appeared in neurons (but not in glia) after MA exposure (Fig. 2B) and are referred to as blebs. Although neuronal blebs were common in MA-treated cultures, they were also apparent in neurons in unhealthy control dishes (not shown). Thus, unlike vacuoles, they were not specifically associated with MA exposure. As shown below, vacuoles and blebs are distinct structures, rather than the same structures at different stages of evolution, as we initially proposed (Cubells et al., 1991).

MA produced swelling and degeneration of DA neuronal processes (Fig. 2; see also Fig. 8). In culture, DA neurons characteristically elaborate processes extending considerable distances, with axon-like neurites often extending over a millimeter (Rayport et al., 1992). After exposure to MA for $6 \mathrm{~d}$, there was a marked loss of DA neuron processes as visualized by TH immunocytochemistry. Counts of the number of neurites extending more than $250 \mu \mathrm{M}$ from their parent cell bodies confirmed 
quantitatively that MA produced widespread process degeneration in a concentration-dependent manner. Incubation in either 100 or $500 \mu \mathrm{M}$ MA for $6 \mathrm{~d}$ produced a dose-dependent increase in the relative frequencies of neurons exhibiting only 1 or 0 neurites reaching the $250 \mu \mathrm{M}$ perimeter (Fig. $3 ; p<0.01$ either for MA concentration compared to control, or for $100 \mu \mathrm{M}$ MA compared to $500 \mu \mathrm{M} \mathrm{MA}$ ).

\section{Acidotropic uptake of $M A$}

In the course of the viability assays, we observed that both vacuoles and blebs characteristically excluded the cytosolic vital stain calcein AM, suggesting that these structures were membrane delimited. Since amphiphilic weak bases such as ammonia (added as $\mathrm{NH}_{4} \mathrm{Cl}$ ) produce osmotic swelling after accumulating in acidic organelles, particularly endosomes and lysosomes (Okhuma and Poole, 1981; Sulzer and Holtzman, 1989), we hypothesized that vacuoles and blebs might arise from these organelles due to acidotropic uptake of MA.

To test this, we labeled cndocytic organelles with fluorescent latex microspheres. The microspheres, which are taken up endocytically in to lysosomes (Egensperger and Hollånder, 1988), produced a punctate pattern of fluorescence in both neurons and glia in control cultures (Figs. 4, 5), similar to that seen with the weak base vital dye acridine orange (Sulzer and Rayport, 1990; Sulzer et al., 1993). In MA-treated cultures, vacuoles were microsphere labeled (Fig. 4) while blebs were never labeled.

Since vacuolation also occurred in astrocytes, we took advantage of their two-dimensional morphology and large endocytic compartments to compare the effects of MA and other weak bases (Okhuma and Poole, 1981; Cain and Murphy, 1986; Sulzer and Holtzman, 1989). Individual astrocytes were identified after uptake of fluorescent latex microspheres, imaged, exposed to the test compounds, and reimaged. MA produced increases in the diameter of endocytic organelles similar to the prototypic vacuologenic weak base ammonia (added as ammonium chloride), whereas the nonvacuologenic weak base tributylamine did not (Fig. 5), demonstrating that MA is a vacuologenic weak base.

\section{MA-induced oxygen radical formation}

To examine whether MA promotes oxidative stress in cultured neurons, we used DCF, a membrane-permeant fluorogenic compound that is trapped in living cells following deesterification by cytoplasmic enzymes. In the presence of hydroperoxides or hydroxyl radicals, 2,7-dichlorofluorescin (deesterified DCF) is converted to the fluorescent compound 2,7,-dichlorofluorescein (Cathcart et al., 1983). If cytoplasmic DA levels increase, we would expect to see increased production of hydroperoxides or free radicals following MA administration.

To determine if DCF responds to DA auto-oxidation, we measured the fluorescence of deesterified DCF in the presence of 0,1 , and $10 \mathrm{~mm}$ DA. Fluorescence increased in a time- and concentration-dependent manner (Fig. 6), demonstrating that DCF detects DA auto-oxidation products. Since hydrogen peroxide increases DCF fluorescence within seconds (Cathcart et al., 1983), the slow buildup of fluorescence likely reflects DA breakdown.

In control VTA cultures incubated with DCF, fewer than $1 \%$ of the neurons were brightly labeled, whereas labeled neurons were common after MA. Figure 7 shows Nomarski and fluorescent images of a group of ventral midbrain neurons incubated for $12 \mathrm{hr}$ in $100 \mu \mathrm{M} \mathrm{MA}$ and then with DCF. The lower-most
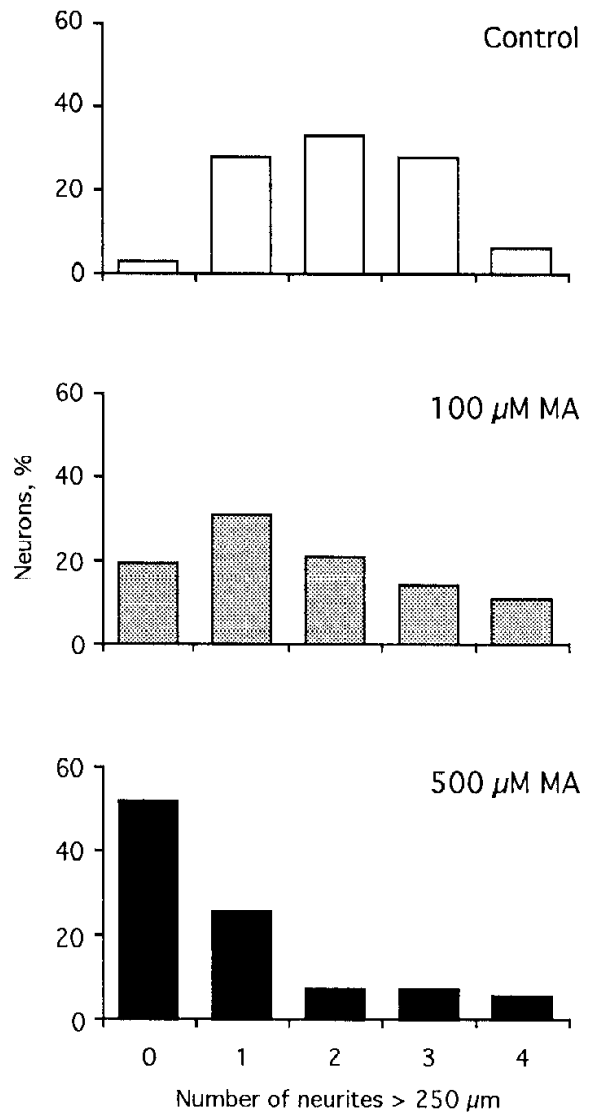

Figure 3. Quantification of process loss from DA neurons following MA exposure. Cultures were exposed to 100 or $500 \mu \mathrm{M}$ MA for $6 \mathrm{~d}$ and immunostained for TH. DA neurons were then classified by the number of neurites that extended beyond a $250 \mu \mathrm{m}$ radius. Relative frequencies of MA-treated DA neurons classified in this way differed significantly from those expected on the basis of the control sample (100 $\mu \mathrm{M}: \chi^{2}=$ $\left.13.89, \mathrm{df}=5, p<0.01 ; 500 \mu \mathrm{M}: \chi^{2}=102.5, \mathrm{df}=5, p<0.001\right)$. In addition, the $500 \mu \mathrm{M}$ group exhibited a different frequency distribution than did the $100 \mu \mathrm{M}$ group $\left(\chi^{2}=33.4, \mathrm{df}=5, p<0.001\right)$. As shown in Figure 2, those differences reflected MA-induced reductions in both the number and extent of $\mathrm{TH}^{+}$neurites.

neuron shows diffuse cytoplasmic labeling with brighter spots of fluorescence localized in an endocytic pattern. The heterogeneity of DCF fluorescence apparent in this group of neurons was typical of that observed in MA-treated ventral midbrain cultures. Astrocytes showed minimal staining. Discrete intracellular DCF labeling was also apparent in neurites. In a representative DCF-labeled VTA neuron after $48 \mathrm{hr}$ in $10 \mu \mathrm{M} \mathrm{MA}$, several blebs were visible along the main neurite (presumably a swollen axon since it extended over $500 \mu \mathrm{m}$ ) as well as vacuoles within the cell body (Fig. 8). All of the blebs, as well as many of the vacuoles, were prominently DCF labeled, demonstrating the presence of high levels of hydroperoxides or oxygen radicals within these presumably MA-induced structures. This pattern of intense punctate DCF labeling was never observed in control cultures.

\section{$M A$ induces oxidative stress selectively in DA neuron cultures}

If the MA-induced increase in oxidative stress is DA mediated, MA should promote hydroperoxide formation only in cultures of DA-containing neurons. To examine this, we conducted preliminary experiments using the TH inhibitor $\alpha$-methyl-p-tyrosine; however, we found that it also alkalinized intracellular 

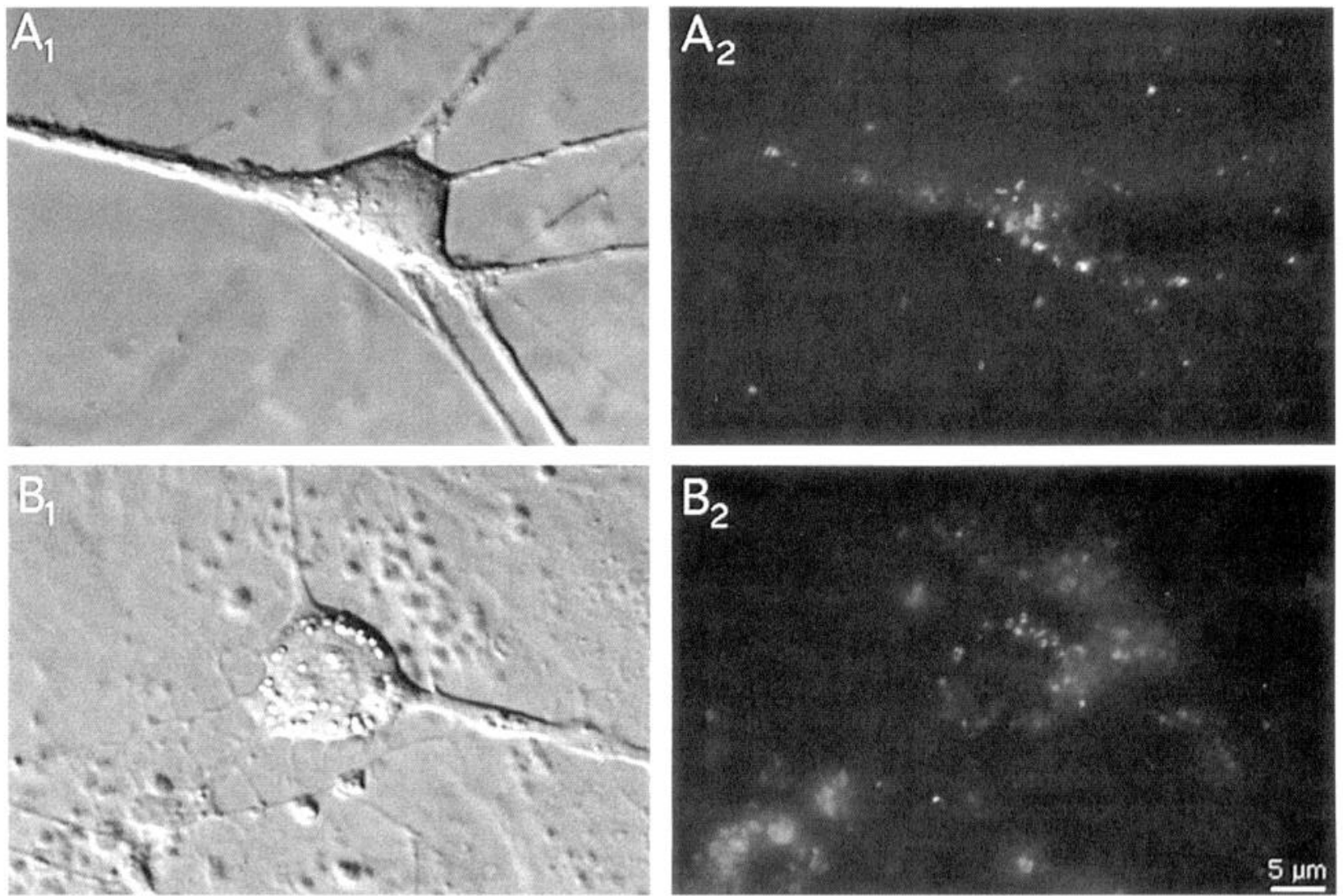

Figure 4. MA causes vacuolation of endocytic compartments. $A_{l}$, A representative neuron from a control ventral midbrain culture appears relatively smooth under Nomarski optics. $A_{2}$, Under fluorescein optics, endocytic compartments are identified in the same control cell using fluorescent latex microspheres as an endocytic label. $B_{l}$, A representative neuron from another ventral midbrain culture exposed to $500 \mu \mathrm{M}$ MA for $24 \mathrm{hr}$. Prominent vacuoles are seen in both the neuron and in the glial monolayer. $B_{2}$, Under fluorescein optics, many of the vacuoles in B1 are labeled by microspheres, thus demonstrating that they arise from endocytic organelles. In contrast, blebs were never microsphere labeled (not shown), suggesting they do not arise from endocytic structures.

acidic compartments. We therefore compared VTA cultures (approximately $30 \%$ DA neurons) to control cultures from their principal target area, the nAcc ( $0 \%$ DA neurons). The cultures contained similar densities of neurons, were derived from the same animals, and were treated in parallel. Neurons in VTA or nAcc cultures showed low rates of neuronal DCF labeling in the absence of MA (Fig. 9). After $48 \mathrm{hr}$ incubation in $10 \mu \mathrm{M}$ MA, VTA cultures exhibited dramatically higher proportions of fluorescent neurons, whereas no increase occurred in nAcc cultures (Fig. 9; $p<0.001$; see caption for statistical details).

To determine if non-DA neurons in VTA cultures also undergo increased oxidative stress, VTA cultures were treated with $\mathrm{MA}$ and subsequently processed to identify DA neurons by $\mathrm{TH}$ antigenicity. After $10 \mu \mathrm{M}$ MA for $2 \mathrm{~d}$, a significantly greater proportion of DA neurons $(40 \%, 14$ of 35$)$ were DCF labeled than of neurons overall $\left(25 \%, 25\right.$ of $101 ; \chi^{2}=5.87, \mathrm{df}=1$, $p<0.025$; Fig. 10).

\section{Discussion}

To focus on the role of DA in MA neurotoxicity, we have examined the effects of MA on postnatal mesolimbic DA neuron cultures maintained under continuous excitatory amino acid (EAA) receptor blockade. We found that MA is a vacuologenic weak base, accounting for its propensity to induce vacuolation of endocytic organelles. In addition, alkalization of acidic in- tracellular gradients may have a range of deleterious effects on cellular metabolism. However, neither of these effects are DA dependent. In contrast, MA induces a DA-dependent increase in intracellular oxidative stress at discrete intracellular sites, particularly in neuronal processes, which may be the initial step in MA neurotoxicity.

\section{Validity of model system}

The neurotoxic effects of MA in EAA-blocked postnatal mesolimbic cultures resemble those seen in more intact preparations. Several studies have examined the morphological consequences of MA administration in vivo. Ricaurte et al. (1982, 1984) showed that MA induces degeneration of ascending DA axons in the nigrostriatal and mesoaccumbens projections but no reduction in the number of neuronal cell bodies in the $\mathrm{SN}$ or VTA. Selective MA-induced process degeneration has been confirmed in a range of studies (Ellison et al., 1978; Lorez, 1981; Hess et al., 1990; cf. Dawirs et al., 1991). The selectivity of MA neurotoxicity for neuronal processes is consistent with the observations of Kontur et al. (1987, 1991), who found MA-induced depletion of DA levels in embryonic midbrain reaggregate cultures after $100 \mu \mathrm{M}$ for $7 \mathrm{~d}$, but no decrement in the number of DA cell bodies. As seen in vivo, we found that DA neurons exposed to MA for $6 \mathrm{~d}$ in culture exhibited a dose-dependent loss of neurites but a low incidence of cell death. This obser- 

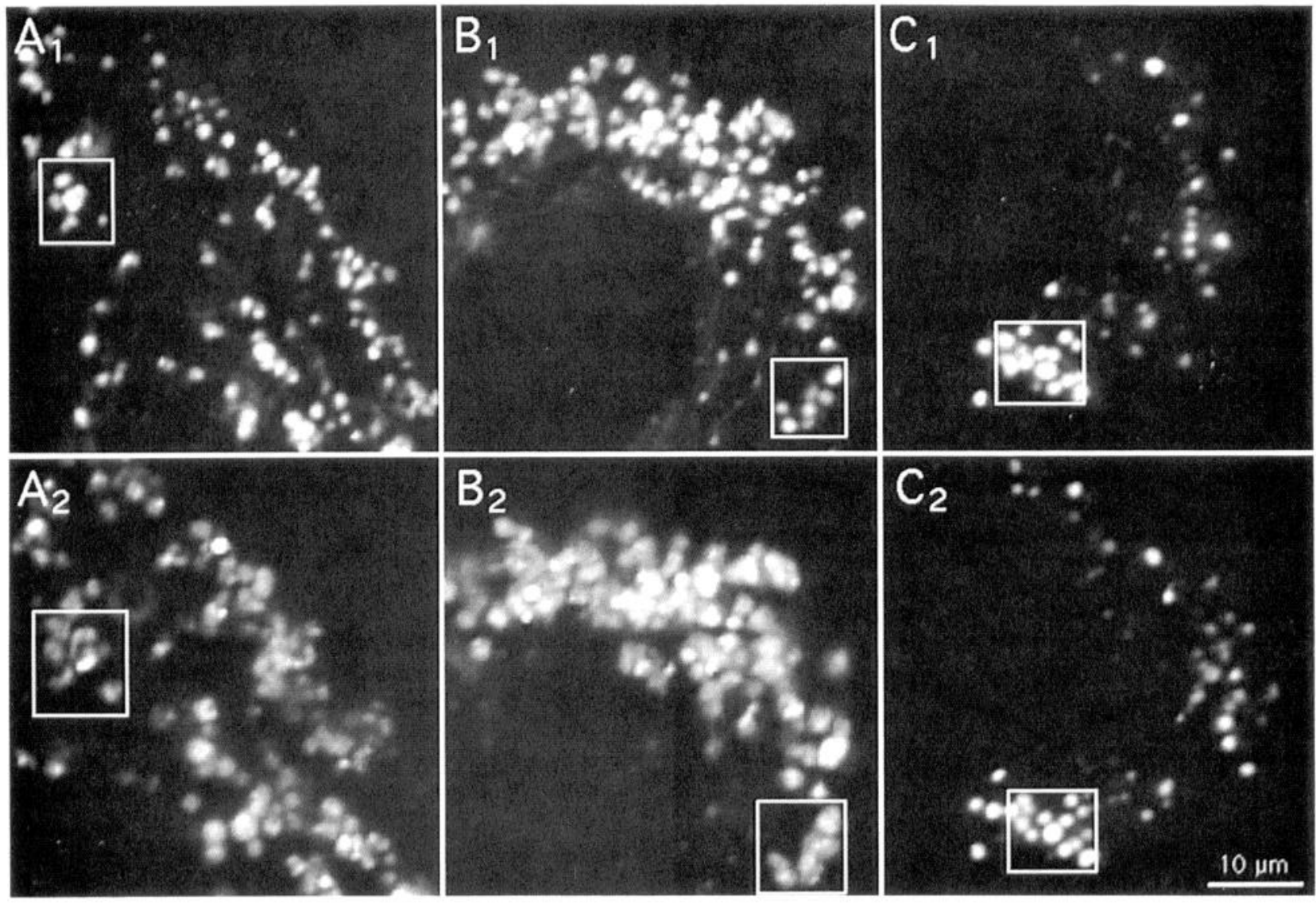

Figure 5. Amphiphilic weak bases cause vacuolation of endocytic organelles. Astrocytes, like neurons, show vacuolation with weak base exposure; because of their flat morphology, changes in the size of endocytic compartments can be followed easily. Each pair of micrographs shows an area of the same cortical astrocyte before and after exposure to weak bases. For comparison, rectangles delineate clusters of the same organelles. $A_{l}, B_{l}$, and $C_{1}$, Astrocytes from sister cultures labeled by uptake of fluorescent microspheres, prior to the addition of the weak bases. $A_{2}$, MA (500 $\mu \mathrm{M}$ for $1.5 \mathrm{hr}$ ) induces swelling of labeled endocytic compartments. $B_{2}$, The classic vacuologenic weak base ammonia (added as $10 \mathrm{mM} \mathrm{NH}_{4} \mathrm{Cl}$ for $2.5 \mathrm{hr}$ ) also causes marked swelling. $C$, In contrast, the lipophilic weak base tributylamine (10 $\mathrm{mm}$ for $2.5 \mathrm{hr})$ does not cause swelling, although at this concentration it abolishes intracellular $\mathrm{pH}$ gradients (Sulzer et al., 1993).

vation provides a useful criterion for in vitro neurotoxicity induced by neuropharmacologically relevant levels of MA.

In our experiments, significant neuronal mortality did not occur except in the presence of concentrations of MA higher than those that arise in the brain $(\geq 500 \mu \mathrm{M})$ with standard pharmacologic doses (10-100 $\mu \mathrm{M}$ after dosages of $1-10 \mathrm{mg} / \mathrm{kg}$ in the rat; Melega et al., 1992), although possibly in the range of concentrations reached in the brains of tolerant abusers during binges (Baselt, 1982). The kynurenate in the culture medium may have exerted a neuroprotective effect; whole-cell, patchclamp observations in midbrain cultures (D. Sulzer and S. Rayport, unpublished observations) confirm that this concentration of kynurenate blocks both NMDA and AMPA-type glutamate receptors. In addition, extracellular superoxide dismutase or catalase in our culture medium may have imparted an increased tolerance to MA exposure.

\section{Neurotoxicity associated with acidotropic MA uptake}

Acidotropic uptake of MA would be expected to increase the osmotic gradient in acidic organelles causing an influx of water, and producing vacuolation identical to that seen with the classic weak base ammonia (Okhuma and Poole, 1981; Sulzer and Holtzman, 1989). We found that both MA- and ammoniuminduced swelling occurred specifically in endocytic organelles.

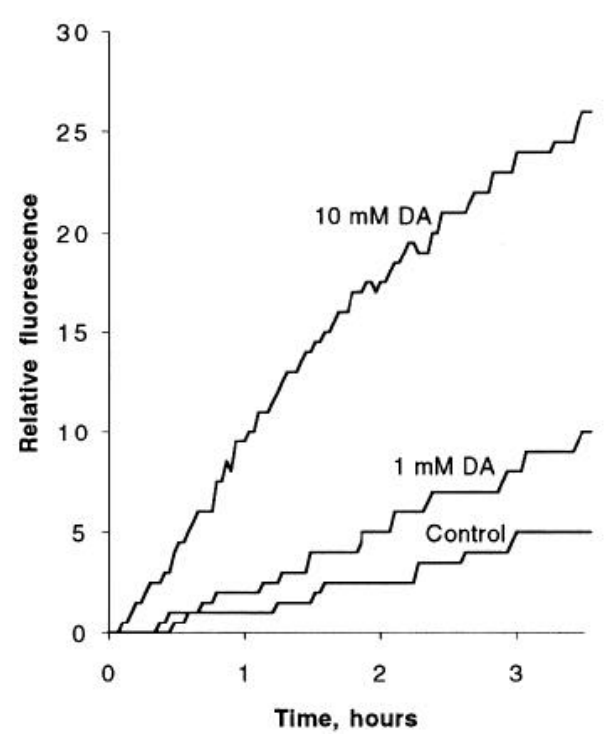

Figure 6. Fluorescent detection of DA auto-oxidation products in vitro. DCF was deesterified and its fluorescence followed in a spectrophotometer for $3 \mathrm{hr}$ (excitation $\lambda=505 \mathrm{~nm}$; emission $\lambda=525 \mathrm{~nm}$ ). The slow increase in DCF fluorescence was accelerated by DA in a concentrationdependent manner, probably reflecting the rate of DA auto-oxidation. 

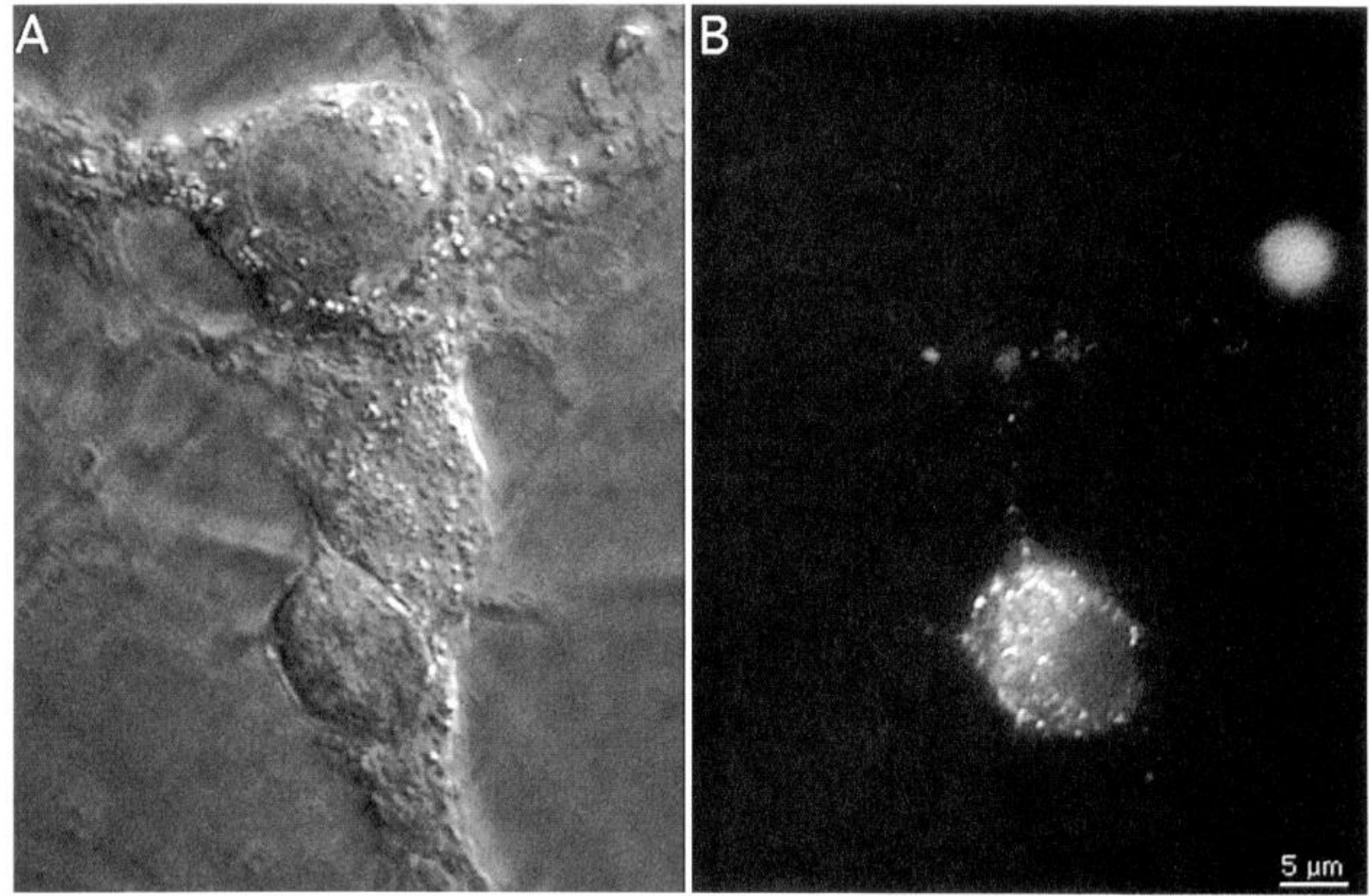

Figure 7. Intracellular oxidative stress due to MA. $A$, A cluster of living ventral midbrain neurons were exposed to $100 \mu \mathrm{M}$ MA for 12 hr. Vacuolation is evident under Nomarski optics. $B$, The same field under fluorescein optics shows that only one neuron is labeled by DCF. The distribution is strikingly similar to that of endocytic organelles (compare Fig. 4). Some structures within the glial monolayer are lightly labeled. In control cultures, fewer than $1 \%$ of neurons were brightly labeled; about $6 \%$ neurons showed light labeling (compare Fig. 9).

In contrast, tributylamine, a nonvacuologenic weak base that is not trapped because it remains lipophilic in its protonated form, did not produce vacuolation. If lysosomal swelling resulted in leakage of degradative enzymes into the cytoplasm, as has been reported in gout and silicosis (Kane et al., 1980; cf. De Duve et al., 1974), vacuolation could play a direct role in MA toxicity. However, we never observed release of the endocytic tracer to the cytosol, arguing against large-scale lysosomal leakage. Other effects following alkalization of intracellular acidic compartments could disrupt $\mathrm{pH}$-dependent metabolic functions vital to cellular function including protein glycosylation, membrane transport, and uptake of growth factors. Similar conditions have been suggested to occur in cystic fibrosis, perhaps due to the impaired acidification in endocytic organelles and Golgi (Barasch et al., 1991). However, these effects are not specific to DA neurons and are probably too slow to account for the relatively rapid toxicity seen with MA.

We suspect that vacuolation per se does not induce MA neurotoxicity since both vacuologenic weak bases such as chloroquine and nonvacuologenic weak bases such as tributylamine similarly inhibit fibroblast growth (Cain and Murphy, 1986). However, alkalization-induced lysosomal storage disorders (Kodavanti and Mehendale, 1990) could contribute nonspecifically to MA neurotoxicity. Lysosomal alkalization by psychostimulants might also account for lipofuscin-containing spherical inclusions seen after administration of methylenedioxymethamphetamine to primates (Ricaurte and McCann, 1992).

\section{$M A$ neurotoxicity due to $D A$ redistribution and oxidative stress}

DA has long been thought to play a role in MA neurotoxicity. Blocking DA synthesis protects against MA toxicity (Gibb and Kogan, 1979; Fuller and Hemrick-Luecke, 1982; Schmidt et al., 1985). DA uptake blockers antagonize MA toxicity (Marek et al., 1990; Fuller, 1991), possibly by reducing MA uptake (Zaczek et al., 1991) or by inhibiting MA-induced reverse transport of DA or DA metabolites (Sulzer et al., 1993). DA oxidation has been implicated in MA toxicity by experiments showing that in vivo administration of antioxidants such as ascorbate and vitamin $\mathrm{E}$ inhibit MA-induced reduction in brain levels of DA (De Vito and Wagner, 1989), and because catalase and superoxide dismutase, enzymes that metabolize hydrogen peroxide and superoxide, respectively, reduce toxicity due to elevated levels of extracellular catecholamines in cortical cultures (Rosenberg, 1988).

How MA interacts with intracellular DA pools directly bears on mechanisms of neurotoxicity. As opposed to the exchange diffusion model of amphetamine action (Fischer and Cho, 1979; Liang and Rutledge, 1982), where amphetamine would reduce cytoplasmic DA levels, in the weak base model amphetamines disrupt the electrochemical gradient that provides energy for monoamine accumulation in synaptic vesicles, leading to a redistribution of DA to the cytosol (Sulzer and Rayport, 1990; Sulzer et al., 1992b). Catecholamines more readily oxidize under cytoplasmic conditions (neutral $\mathrm{pH}$, low ascorbate levels, and availability to MAO) than under intravesicular conditions (low 


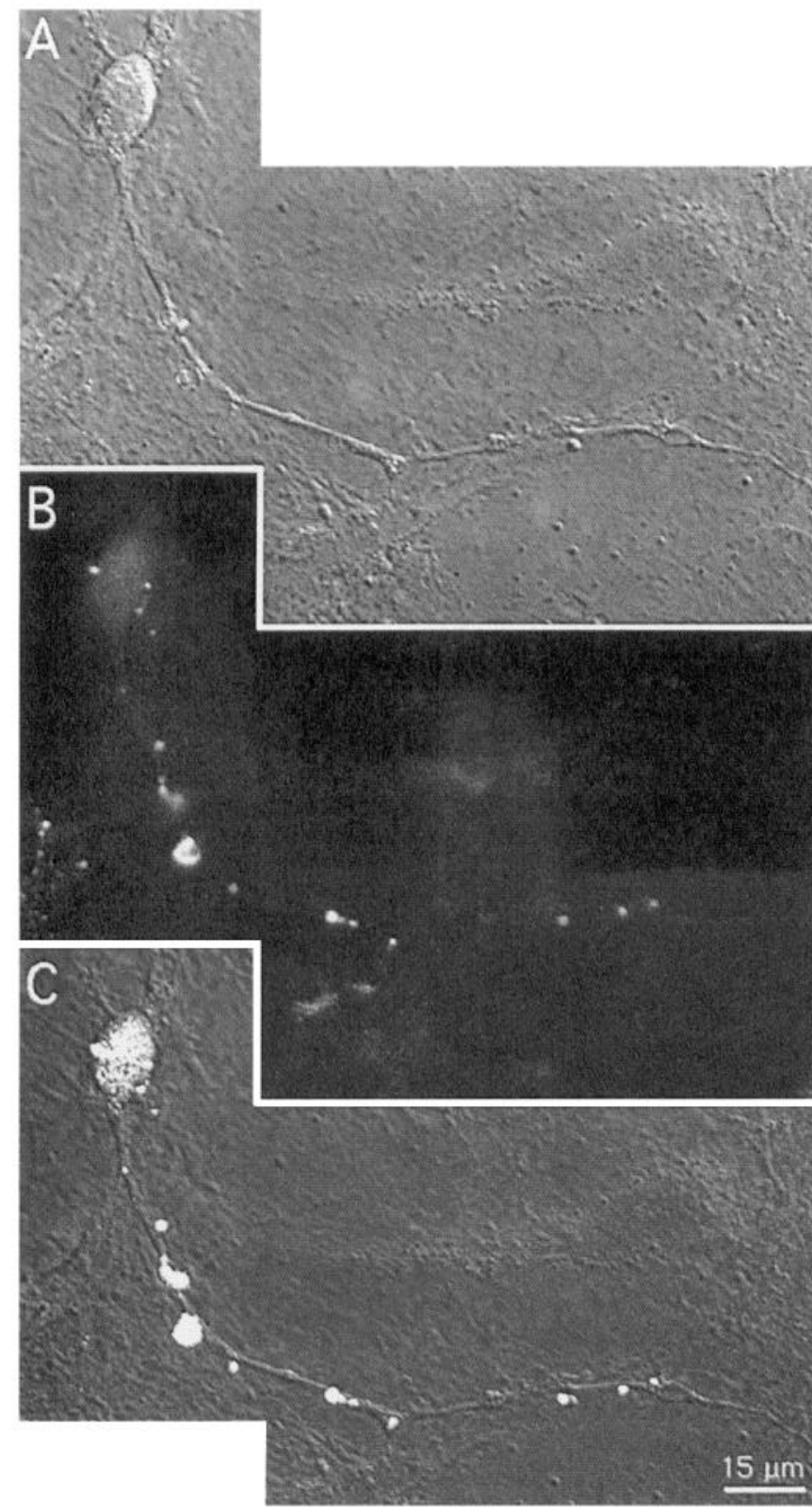

Figure 8. Discrete sites of MA-induced oxidative stress in neuronal processes. $A$, Under Nomarski optics, a neuronal process from a ventral midbrain culture exposed to $10 \mu \mathrm{M}$ MA for $48 \mathrm{hr}$ is swollen, particularly at varicosities, and has several blebs. $B$, Under fluorescein optics, DCF label is seen at discrete sites in the cell body and process. $C$, Superposition of $A$ and $B$ with digital enhancement of the DCF fluorescence shows the presence of label in most blebs and varicosities, demonstrating localized oxidative stress within the process. In the cell body, DCF labeling is present in a punctate distribution similar in pattern to the distribution of endocytic organelles as well as diffusely in the cytoplasm.

$\mathrm{pH}$, high ascorbate levels, and no exposure to MAO). DA autooxidation leads to formation of reactive quinone derivatives, hydrogen peroxide, and free radicals (Graham et al., 1978; Slivka and Cohen, 1985). Therefore, after overwhelming cytoplasmic antioxidant systems, DA redistributed to the cytosol could increase oxidative stress.

We have shown that DA in solution undergoes auto-oxidation, resulting in the production of hydroperoxides or free radicals that oxidize the hydroperoxide-sensitive vital probe DCF

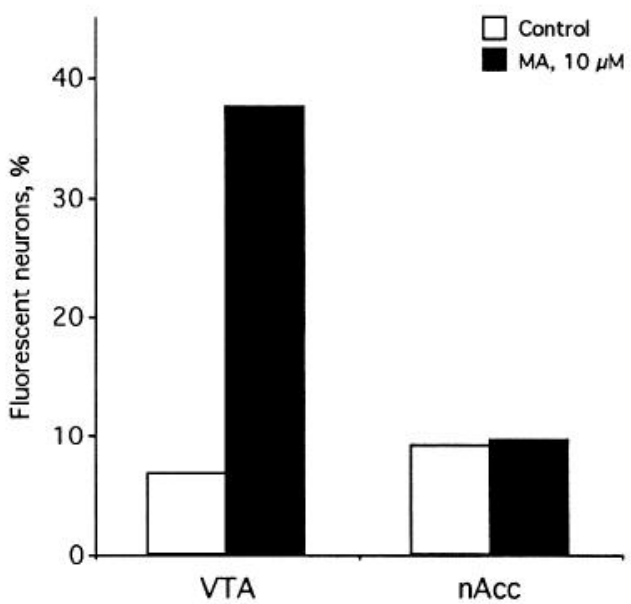

Figure 9. MA-induced oxidative stress is DA dependent. $A$, Sister VTA cultures ( $~ 30 \%$ DA neurons) and nAcc cultures ( $0 \%$ DA neurons) were treated with $10 \mu \mathrm{M}$ MA for $48 \mathrm{hr}$. MA-treated VTA cultures showed a fivefold increase in the proportion of neurons labeled by DCF compared to control $\left(\chi^{2}=432.9, \mathrm{df}=1, p \ll 0.001\right)$, whereas the nAcc cultures showed no MA-induced increase $\left(\chi^{2}=0.035, \mathrm{df}=1\right.$, NS). An observer blind to treatment condition counted total and DCF-positive neurons; $n=900$ neurons in three sister cultures per condition. The experiment was repeated three times with similar results.

to its fluorescent form. DCF has been used previously to detect intracellular production of hydroperoxides in non-neural cell types (Cathcart et al., 1983; Saito et al., 1992) and in a neuroblastoma-retinal hybrid cell line (Murphy et al., 1989). Applying DCF to neuronal culture, we demonstrate for the first time the presence of discrete intracellular sites of oxidative stress in neurons. These observations directly implicate intracellular compartments within aminergic neurons as important sites of MAinduced production of free radicals, in addition to the previously suggested extracellular sites (Seiden and Ricaurte, 1987), and bear out a prediction recently made by Fuller (1991) that MA may induce intracellular oxidative stress.

The varicosities in putative axonal processes are prominent hot spots of MA-induced hydroperoxides. This observation suggests a basis for the differential sensitivity of DA fibers to MA toxicity in vivo. Varicosities contain numerous mitochondria and are densely packed with synaptic vesicles that accumulate 5-hydroxydopamine (Arluison et al., 1978; Sulzer and Rayport, 1990; Rayport et al., 1992). Redistribution of DA from synaptic vesicles could overwhelm cytosolic antioxidant systems in axonal varicosities, leading to local DA auto-oxidation. MAO in the numerous mitochondria present in varicosities might contribute further to local oxidative stress by catalyzing the stoichiometric formation of hydrogen peroxide during the conversion of DA to DOPAC (Cooper et al., 1991). However, MAO inhibitors are not effective antagonists of MA neurotoxicity (Fuller, 1991), and MA itself inhibits MAO at high concentrations (Leitz and Stefano, 1971). Thus, intact MAO activity per se does not appear to be a prerequisite for MA neurotoxicity.

MA-induced DCF labeling in the cell body mostly appears in a distribution identical to that of endocytic organelles (i.e., endosomes and lysosomes). Lighter and more diffuse cytoplasmic labeling is also seen. The accumulation of label into endocytic organelles is probably due to lipophilic uptake since it appears to occur far too rapidly to reflect extensive endocytosis. Once inside lysosomes, deesterified DCF (dichlorofluorescin) might also selectively accumulate due to lysosomal esterases. 


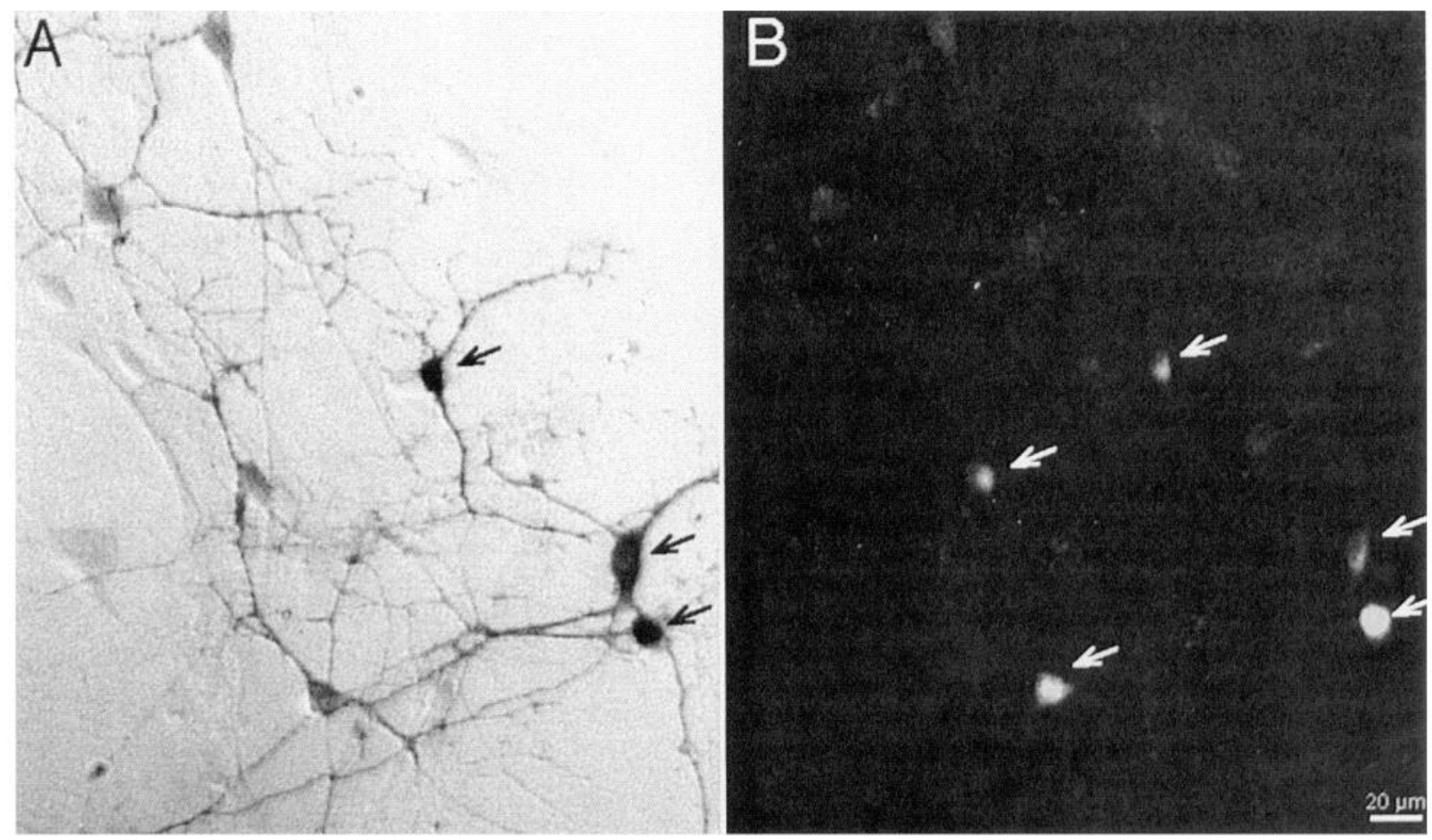

Figure 10. In ventral midbrain cultures, both DA and non-DA neurons undergo MA-induced oxidative stress. $A$, In a culture treated with $10 \mu \mathrm{M}$ MA for $48 \mathrm{hr}$, TH immunocytochemistry shows that three cells in the field are DA neurons (arrows). Note the elaboration of varicosity-studded processes that appear to contact TH-negative neurons. $B$, When the same field, prior to fixation, is examined after DCF application, five neurons are labeled by DCF (arrows), two brightly so. The labeled neurons include all three DA neurons; the labeled non-DA neurons appear to be in contact with DA varicosities. Unlabeled neurons show low levels of fluorescence, which at higher magnification does not appear to be localized to intracellular structures.

Alternatively, MA-induced alkalization might promote formation of high levels of DA-derived free radicals and hydroperoxides within lysosomes and other acidic compartments, perhaps because the hydroxyl radical is a weak acid $(\mathrm{pK}=4.7)$ most reactive in its protonated form (cf. Cohen, 1984).

DA appears to translocate into the cytosol and extracellular space within minutes after amphetamine administration (Sulzer et al. 1992a, 1993) while DCF oxidation is apparent within seconds in the presence of hydroperoxides (Cathcart et al., 1983). However, we noticed increases in DCF fluorescence within ventral midbrain cultures only after $12-24 \mathrm{hr}$ of exposure to $10 \mu \mathrm{M}$ MA (data not shown), with maximal increases in DCF fluorescence occurring $48 \mathrm{hr}$ post-MA. One possible explanation for this delay is that intracellular antioxidants such as glutathione (Murphy et al., 1991) mitigate DA oxidation within aminergic neurons such that DA-derived reactive metabolites must accumulate with continued exposure to MA until they overwhelm the buffering capacity of intracellular antioxidant systems.

\section{Cellular consequences of oxidative stress}

Our results demonstrate that pharmacologically relevant levels of MA increase local DA-dependent oxidative stress. Intracellular reactive metabolites are likely to degrade cellular components, including mitochondria (Wallace, 1992) and microtubules that are important for axonal cytoskeletal maintenance. Mechanisms explaining MA-induced damage to dendrites are less clear. We have not observed dendritic DA synaptic vesicles in culture (Sulzer and Rayport, 1990; Rayport et al., 1992) but dendrites may store DA in cisternal organelles (Cheramy et al.,
1981). Degeneration of dendrites might depend on local DA stores, distribution of DA uptake sites, high surface area to volume ratio, or susceptibility of cytoskeletal elements to oxidative damage.

Based on the selective DCF labeling of DA neuron cultures, MA-induced formation of hydroperoxides or oxygen radicals appears to be DA dependent. However, non-DA neurons within the MA-treated DA cultures also exhibit DA-dependent increases in DCF labeling. Often DCF-labeled non-DA neurons receive afferents from DA neurons (see Fig. 10), suggesting that release of DA or DA metabolites could induce transynaptic oxidative stress in non-DA neurons. As amphetamines release DA from synaptic terminals, it may be that local MA-induced increases in extracellular DA are sufficient to overcome extracellular superoxide dismutase and catalase, which attenuate catecholamine toxicity (Rosenberg, 1988); alternatively, reactive DA or DOPA derivatives such as 6-OHDA, 2,4,5-trihydroxyphenylalanine, or quinones and semiquinones might be released from cells or produced extracellularly (Seiden and Ricaurte, 1987; Olney et al., 1990; Rosenberg et al., 1991). Such mechanisms could play a role in degeneration of neurons receiving DA afferents in striatonigral degeneration (Weiner and SanchezRamos, 1992).

Along with process degeneration and vacuolation, MA induces blebs similar in appearance to those seen during cell death due to chemical hypoxia (Jurkowitz-Alexander et al., 1992) and apoptosis (Wyllie et al., 1980). These structures are generally presumed to arise from deformation of the plasma membrane after cytoskeletal breakdown. The blebs in our experiments ex- 
cluded calcein AM, suggesting they are not continuous with the cytoplasm. In contrast to vacuoles, blebs never contained endocytic tracers, implying they did not arise from endocytic organclles. Regardless of whether they occur in MA-treated or control cultures, blebs nearly always exhibit strikingly intense DCF fluorescence, suggesting that hydroperoxides play a role in their formation. Possibly the blebs arise from organelles involved in lipid peroxidation, although a plasma membrane origin cannot be excluded.

Although the present study focuses on MA, similar effects could occur with other weak base drugs toxic to monoamine systems including fenfluramine, $N$-methyl-4-phenyl-1,2,3,6-tetrahydropyridine, methylenedioxymethamphetamine, phencyclidine, and chloroquine, as well as in disorders including Parkinson's disease and striatonigral atrophies (Graham, 1984; Spina and Cohen, 1989; Przedborski et al., 1992; Storey et al., 1992; Weiner and Sanchez-Ramos, 1992). Recently, Beitner-Johnson et al. (1992) found that chronic cocaine decreased neurofilament proteins in midbrain DA regions, suggesting that cocaine may also selectively damage neuronal processes.

\section{Role of EAAS}

NMDA antagonists protect against MA-induced reduction of striatal DA content and TH activity in vivo (Sonsalla et al., 1989, 1991), pointing to a role for EAAs in MA neurotoxicity. However, excitotoxicity per se does not appear to account for MA neurotoxicity. First, we see MA-induced morphological changes in postnatal DA neuron cultures in the presence of glutamate receptor blockade. Second, in contrast to the sclcctive destruction of DA terminals by MA in culture or in vivo, striatal injections of excitotoxins such as kainate, ibotenate, and quinolinate destroy cell bodies but spare DA terminals (Olney et al., 1974; Coyle et al., 1978; Schwarcz et al., 1983). Third, excitotoxins are not selective for DA processes either in culture or in the striatum. Rather, our evidence suggests that intracellular DA-dependent oxidative stress may be sufficient to explain the selectivity of MA toxicity for DA terminals.

$\triangle \mathrm{DA}$-dependent model of MA neurotoxicity may well be consistent with the role demonstrated for EAAs in vivo (Sonsalla et al., 1989, 1991). For example, the NMDA antagonist MK801 might protect striatal DA terminals by inhibiting an NMDAdependent increase in DA release (Bowyer et al., 1991; O'Dell et al., 1992; Weihmuller et al., 1992a,b; Marshall et al., 1993). Tonic NMDA stimulation could increase TH activity, as has been reported with electrical stimulation (Goldstein and Greene, 1987), thereby promoting MA-induced DA release. Oxidative stress could promote neuronal depolarization, leading to NMDA receptor activation and downstream excitotoxicity (Watkins and Collingridge, 1989). Whatever the precise role of EAAs, our observation that MA induces DA-dependent intracellular oxidative stress in the presence of EAA receptor blockade suggests that redistribution of DA from synaptic vesicles to the cytoplasm may be the initiating step in MA neurotoxicity.

\section{References}

Arluison M, Agid Y, Javoy F (1978) Dopaminergic nerve endings in the neostriatum of the rat-1. Identification by intracerebral injections of 5-hydroxydopamine. Neuroscience 3:657-673.

Barasch J, Kiss B, Prince A, Saiman L, Gruenert D, Al-Awqati Q (1991) Defective acidification of intracellular organelles in cystic fibrosis. Nature 352:70-73.

Baselt RC (1982) Disposition of toxic drugs and chemicals in man. Davis, CA: Biomedical Publications.
Baughman RW, Huettner JE, Jones KA, Khan AA (1991) Cell culture of neocortex and basal forebrain from postnatal rats. In: Culturing nerve cells (Banker G, Goslin K, eds), pp 227-250. Cambridge, MA: MIT Press.

Beers MF, Johnson RG, Scarpa A (1986) Evidence for an ascorbate shuttle for the transfer of reducing equivalents across chromaffin granule membranes. J Biol Chem 261:2529-2535.

Beitner-Johnson D, Guitart X, Nestler EJ (1992) Neurofilament proteins and the mesolimbic dopamine system: common regulation by chronic morphine and chronic cocaine in the rat ventral tegmental area. J Neurosci 12:2165-2176.

Bennett BA, Hyde CE, Pecora JR, Clodfelter JE (1993) Differing neurotoxic potencies of methamphetamine, mazindol, and cocaine in mesencephalic cultures. J Neurochem 60:1444-1452.

Bowyer JF, Scallet AC, Holson RR, Lipe GW, Slikker W, Ali SF (1991) Interactions of MK-801 with glutamate-, glutamine- and methamphetamine-evoked release of $\left[{ }^{3} \mathrm{H}\right]$ dopamine from striatal slices. J Pharmacol Exp Ther 257:262-270.

Cain CC, Murphy RF (1986) Growth inhibition of 3 T3 fibroblasts by lysosomotropic amines: correlation of effects on intravesicular $\mathrm{pH}$ but not vacuolation. I Cell Physiol 129:65-70.

Cathcart R, Schwiers E, Ames BN (1983) Detection of picomole levels of hydroperoxides using a fluorescent dichlorofluorescein assay. Anal Biochem 134:111-116.

Cheramy A, Leviel V, Glowinski J (1981) Dendritic release of dopamine in the substantia nigra. Nature 289:537-542.

Cho AK (1990) Ice: a new dosage form of an old drug. Science 249 : 631-634.

Cohen G (1984) Oxy-radical toxicity in catecholamine neurons. Neurotoxicology 5:77-82.

Cooper JR, Bloom FE, Roth RH (1991) The biochemical basis of neuropharmacology. New York: Oxford UP.

Coyle JT, Molliver ME, Kuhar M (1978) In situ injection of kainic acid: a new method for selectively lesioning neuronal cell bodies while sparing axons of passage. J Comp Neurol 180:301-324.

Cubells JF, Sulzer D, Rayport S (1991) Methamphetamine cytotoxicity studied in cultured rat ventral midbrain neurons. Soc Neurosci Abstr 17:191.

Dawirs RR, Teuchert-Noodt G, Busse M (1991) Single doses of methamphetamine cause changes in the density of dendritic spines in the prefrontal cortex of gerbils (Meriones unguiculatus). Neuropharmacology 30:275-282.

De Duve C, DeBarsy T, Polle B, Trouet A, Tulkens P, Van Hoof F (1974) Lysosomotropic agents. Biochem Pharmacol 23:2495-2531.

De Vito MJ, Wagner GC (1989) Methamphetamine-induced neuronal damage: a possible role for free radicals. Neuropharmacology 28 : $1145-1150$.

Dowdy S, Wearden S (1983) Statistics for research. New York: Wiley.

Egensperger R, Hollånder H (1988) Electron microscopic visualization of fluorescent microspheres used as a neuronal tracer. J Neurosci Methods 23:181-186.

Ellison G, Eison MS, Huberman HS, Daniel F (1978) Long-term changes in dopaminergic innervation of caudate nucleus after continuous amphetamine administration. Science 201:276-278.

Fischer JF, Cho AK (1979) Chemical release of dopamine from striatal homogenates: evidence for an exchange diffusion model. J Pharmacol Exp Ther 208:203-209.

Fuller RW (1991) Comparison of MPTP and amphetamines as dopaminergic neurotoxins. Ann NY Acad Sci 648:87-95.

Fuller RW, Hemrick-Luecke SK (1982) Further studies on the longterm depletion of striatal dopamine in iprindole-treated rats by amphetamine. Neuropharmacology 21:433-438.

Gibb JW, Kogan FJ (1979) Influence of dopamine synthesis on methamphetamine-induced changes in striatal and adrenal tyrosine hydroxylase activity. Naunyn Schmiedebergs Arch Pharmacol 310:185187.

Goldstein M, Greene LA (1987) Activation of tyrosine hydroxylase by phosphorylation. In: Psychopharmacology: a third generation of progress (Meltzer HY, ed), pp 75-80. New York: Raven.

Graham DG (1984) Catecholamine toxicity: a proposal for the molecular pathogenesis of manganese neurotoxicity and Parkinson's disease. Neurotoxicology 5:83-96.

Graham DG, Tiffany SM, Bell WR, Gutknecht WF (1978) Autooxidation versus covalent binding of quinones as the mechanism of toxicity of dopamine, 6-hydroxydopamine, and related compounds 
toward C1300 neuroblastoma cells in vitro. Mol Pharmacol 14:644653.

Hess A, Desiderio C, McAuliffe WG (1990) Acute neuropathological changes in the caudate nucleus caused by MPTP and methamphetamine: immunohistochemical studies. J Neurocytol 19:338-342.

Johnson RG (1988) Accumulation of biological amines into chromaffin granules: a model for hormone and neurotransmitter transport. Physiol Rev 68:232-307.

Jurkowitz-Alexander MS, Altschuld RA, Hohl CM, Johnson JD, McDonald JS, Simmons TD, Horrocks LA (1992) Cell swelling, blebbing, and death are dependent on ATP depletion and independent of calcium during chemical hypoxia in a glial cell line. J Neurochem 59:344-352.

Kane AB, Stanton RP, Raymond EG, Dobson ME, Knafelc ME, Farber JL (1980) Dissociation of intracellular lysosomal rupture from the cell death caused by silica. J Cell Biol 87:643-651.

Kodavanti UP, Mehendale HM (1990) Cationic amphiphilic drugs and phospholipid storage disorder. Pharmacol Rev 42:327-354.

Kontur PJ, Hoffmann PC, Heller A (1987) Neurotoxic effects of methamphetamine assessed in three-dimensional reaggregate tissue cultures. Dev Brain Res 31:7-14

Kontur PJ, Won LA, Hoffmann PC, Heller A (1991) Survival of developing dopaminergic neurons in reaggregate tissue culture following treatment with methamphetamine. Neurosci Lett 129:254 258.

Leitz FH, Stefano FJE (1971) The effect of tyramine, amphetamine, and metaraminol on the metabolic disposition of ${ }^{3} \mathrm{H}$-norepinephrine released from the andrenergic neuron. J Pharmacol Exp Ther 178: $464-473$

Liang NY, Rutledge CO (1982) Comparison of the release of $\left[{ }^{3} \mathrm{H}\right]$ dopamine from isolated corpus striatum by amphetamine, fenfluramine, and unlabeled dopamine. Biochem Pharmacol 31:983992.

Lorez H (1981) Fluorescence histochemistry indicates damage of striatal dopamine nerve terminals in rats after multiple doses of methamphetamine. Life Sci 28:911-916.

Marek GJ, Vosmer G, Seiden LS (1990) Dopamine uptake inhibitors block long-term neurotoxic effects of methamphetamine upon dopaminergic neurons. Brain Res 513:274-279.

Marshall JF, O'Dell SJ, Weihmuller FB (1993) Dopamine-glutamate interactions in methampletamine-induced neurotoxicity. J Neural Transm 91:241-254.

Melega WP, Williams AE, Scmitz D, Stefano ED, Cho AK (1992) Pharmacokinetic/pharmacodynamic analysis of $d$-amphetamine and $d$-methamphetamine. Soc Neurosci Abstr 18:363.

Murphy TH, Miyamoto M, Sastre A, Schnaar RL, Coyle JT (1989) Glutamate toxicity in a neuronal cell line involves inhibition of cystine transport leading to oxidative stress. Neuron 2:1547-1558.

Murphy TH, De Long M.I, Coyle JT (1991) Enhanced NAD(P)H: quinone reductase activity prevents glutamate toxicity produced by oxidative stress. J Neurochem 56:990-995.

Njus D, Kelley PM, Harnadek GJ (1986) Bioenergetics of secretory vesicles. Biochim Biophys Acta 853:237-265.

O'Dell SJ, Weihmuller FB, Marshall JF (1992) Multiple methamphetamine injections induce marked increases in extracellular striatal dopamine which correlate with subsequent neurotoxicity. Brain Res 564:256-260.

O'Dell SJ, Weihmuller FB, Marshall JF (1993) MA-induced DA overflow and injury to striatal DA terminals: attenuation by $D_{A} D_{1}$ or $D_{2}$ antagonists. J Neurochem 60:1792-1799.

Okhuma S, Poole B (1981) Cytoplasmic vacuolation of mouse peritoneal macrophages and the uptake into lysosomes of weakly basic substances. J Cell Biol 90:656-664.

Olney JW, Rhee V, Ho OL (1974) Kainic acid: a powerful neurotoxic analogue of glutamate. Brain Res 77:507-512.

Olney JW, Zorummski CF, Stewart GR, Price MT, Wang G, Labruyere J (1990) Excitotoxicity of L-DOPA and 6-OH-DOPA: implications for Parkinson's and Huntington's diseases. Exp Neurol 108:269.

Przedborski S, Kostic V, Jackson-Lewis V, Naini AB, Simonetti S, Fahn S, Carlson E, Epstein CJ, Cadet JL (1992) Transgenic mice with increased $\mathrm{Cu} / \mathrm{Zn}$-superoxide dismutase activity are resistant to $N$-methyl-4-phenyl-1,2,3,6-tetrahydropyridine-induced neurotoxicity. J Neurosci 12:1658-1667.

Rayport S, Sulzer D, Shi WX, Sawasdikosol S, Monaco J, Batson D, Rajendran G (1992) Identified postnatal mesolimbic dopamine neu- rons in culture: morphology and electrophysiology, $\mathrm{J}$ Neurosci 12 : 4264-4280.

Ricaurte GA, McCann UD (1992) Neurotoxic amphetamine analogues: effects in monkeys and implications for humans. Ann NY Acad Sci 648:371-382.

Ricaurte GA, Guillery RW, Seiden LS, Schuster CR, Moore RY (1982) Dopamine nerve terminal degeneration produced by high doses of methylamphetamine in the rat brain. Brain Res 235:93-103.

Ricaurte GA, Seiden LS, Schuster CR (1984) Further evidence that amphetamines produce long-lasting dopamine neurochemical deficits by destroying dopamine nerve fibers. Brain Res 303:359-364.

Rollema H, De Vries JB, Westerink BH, Van Putten FM, Horn AS (1986) Failure to detect 6-hydrox ydopamine in rat striatum after the dopamine releasing drugs dexamphetamine, methylamphetamine and MPTP. Eur J Pharmacol 132:65-66.

Rosenberg PA (1988) Catecholamine toxicity in cerebral cortex in dissociated cell culture. J Neurosci 8:1887-2894.

Rosenberg PA, Loring R, Xie Y, Zaleskas V, Aizenman E (1991) 2,4,5Trihydroxyphenylalanine in solution forms a non- $N$-methyl-D-aspartate glutamatergic agonist and neurotoxin. Proc Natl Acad Sci USA $88: 4865-4869$.

Saito H, Fukumura D, Kurose I, Suematsu M, Tada S, Kagawa T, Miura S, Morizane T, Tsuchiya M (1992) Visualization of oxidative processes at the cellular level during neutrophil-mediated cytotoxicity against a human hepatoma cell line, HCC-M. Int J Cancer 51:124129.

Schmidt CJ, Ritter JK, Sonsalla PK, Hanson GR, Gibb JW (1985) Role of dopamine in the neurotoxic effects of methamphetamine. $J$ Pharmacol Exp Ther 233:539-544.

Schwarcz R, Whetsell WO, Mangano R (1983) Quinolinic acid: an endogenous metabolite that produces axon-sparing lesions in rat brain. Science 219:316-318.

Seiden LS, Ricaurte GA (1987) Neurotoxicity of methamphetamine and relate drugs. In: Psychopharmacology: a third generation of progress (Meltzer HY, ed), pp 359-366. New York: Raven.

Seiden LS, Vosmer G (1984) Formation of 6-hydroxydopamine in caudate nucleus of rat brain after a single large dose of methamphetamine. Pharmacol Biochem Behav 21:29-31.

Slivka A, Cohen G (1985) Hydroxyl radical attack on dopamine. J Biol Chem 260:15466-15472.

Sonsalla PK, Nickas WJ, Heikkila RE (1989) Role for excitatory amino acids in methamphetamine-induced nigrostriatal dopaminergic toxicity. Science 243:398-400.

Sonsalla PK, Riordan DE, Heikkila RE (1991) Competitive and noncompetitive antagonists at $N$-methyl- $D$-aspartate receptors protect against methamphetamine-induced dopaminergic damage in mice. $\mathrm{J}$ Pharmacol Exp Ther 256:506-512.

Spina MB, Cohen G (1989) Dopamine turnover and glutathione oxidation: implications for Parkinson disease. Proc Natl Acad Sci USA 86:1398-1400.

Storey E, Hyman BT, Jenkins B, Brouillet E, Miller JM, Rosen BR, Beal MF (1992) 1-Methyl-4-phenylpyridinium produces excitotoxic lesions in rat striatum as a result of impairment of oxidative metabolism. J Neurochem 58:1975-1978.

Sulzer D, IIoltzman E (1989) Acidification and endosome-like compartments in the presynaptic terminals of frog retinal photoreceptors. J Neurocytol 18:529-540.

Sulzer D, Rayport S (1990) Amphetamine and other psychostimulants reduce $\mathrm{pH}$ gradients in midbrain dopaminergic neurons and chromaffin granules: a mechanism of action. Neuron 5:797-808.

Sulzer D, Lau YY, Ewing AG, Rayport S (1992a) Real-time measurement of amphetamine's effects on transmitter dynamics in the Planorbis giant dopamine neuron. Soc Neurosci Abstr 18:582.

Sulzer D, Pothos E, Sung HM, Maidment NT, Hoebel BG, Rayport S (1992b) Weak base model of amphetamine action. Ann NY Acad Sci 654:525-528.

Sulzer D, Maidment NT, Rayport S (1993) Amphetamine and other weak bases act to promote reverse transport of dopamine in ventral midbrain neurons. J Neurochem 60:527-535.

Wallace DC (1992) Mitochondrial genetics: a paradigm for aging and degenerative diseases? Science 256:628-632.

Watkins JC, Collingridge GL (1989) The NMDA receptor. Oxford: IRL.

Weihmuller FB, O'Dell SJ, Cole BN, Marshall JF (1992a) MK-801 attenuates the dopamine-releasing but not the behavioral effects of 
methamphetamine: an in vivo microdialysis study. Brain Res 549: 230-235.

Weihmuller FB, O'Dell SJ, Marshall JF (1992b) MK-801 protection against methamphetamine-induced striatal dopamine terminal injury is associated with attenuated dopamine overflow. Synapse 11:155163.

Weiner WJ, Sanchez-Ramos J (1992) Movement disorders and dopaminomimetic stimulant drugs. In: Drug-induced movement disorders (Lang AE, Weiner WJ, eds), pp 315-337. Mt. Kisco, NY: Futura.
Wise RA, Hoffman DC (1992) Localization of drug reward mechanisms by intracranial injections. Synapse 10:247-263.

Wyllie AH, Kerr JFR, Currie AR (1980) Cell death: the significance of apoptosis. Int Rev Cytol 68:251-307.

Zaczek R, Culp S, De Souza EB (1991) Interactions of $\left[{ }^{3} \mathrm{H}\right]$ amphetamine with rat brain synaptosomes. II. Active transport. J Pharmacol Exp Ther 257:830-835.

Zar JH (1984) Biostatistical analysis. Englewood Cliffs, NJ: PrenticeHall. 